\title{
ORIGINAL ARTICLE Additive genetic variation in resistance traits of an exotic pine species: little evidence for constraints on evolution of resistance against native herbivores
}

\begin{abstract}
X Moreira ${ }^{1,2}, \mathrm{R}_{\mathrm{Zas}^{2}}$ and L Sampedro ${ }^{3}$
The apparent failure of invasions by alien pines in Europe has been explained by the co-occurrence of native pine congeners supporting herbivores that might easily recognize the new plants as hosts. Previous studies have reported that exotic pines show reduced tolerance and capacity to induce resistance to those native herbivores. We hypothesize that limited genetic variation in resistance to native herbivores and the existence of evolutionary trade-offs between growth and resistance could represent additional potential constraints on the evolution of invasiveness of exotic pines outside their natural range. In this paper, we examined genetic variation for constitutive and induced chemical defences (measured as non-volatile resin in the stem and total phenolics in the needles) and resistance to two major native generalist herbivores of pines in cafeteria bioassays (the phloem-feeder Hylobius abietis and the defoliator Thaumetopoea pityocampa) using half-sib families drawn from a sample of the population of Pinus radiata introduced to Spain in the mid-19th century. We found (i) significant genetic variation, with moderate-to-high narrow-sense heritabilities for both the production of constitutive non-volatile resin and induced total phenolics, and for constitutive resistance against T. pityocampa in bioassays, (ii) no evolutionary trade-offs between plant resistance and growth traits or between the production of different quantitative chemical defences and (iii) a positive genetic correlation between constitutive resistance to the two studied herbivores. Overall, results of our study indicate that the exotic pine $P$. radiata has limited genetic constraints on the evolution of resistance against herbivores in its introduced range, suggesting that, at least in terms of interactions with these enemies, this pine species has potential to become invasive in the future.
\end{abstract}

Heredity (2013) 110, 449-456; doi:10.1038/hdy.2012.108; published online 12 December 2012

Keywords: chemical defences; Hylobius abietis; methyl jasmonate; Pinus radiata; Thaumetopoea pityocampa; trade-offs

\section{INTRODUCTION}

Exotic plant species can rapidly adapt to a new geographic range and frequently outcompete native plants (Maron et al., 2004). The success of exotic plants in their introduced range depends on several biotic and abiotic factors. Among biotic factors, reduced impact of native herbivores is considered one of the primary causes contributing to the success of exotic plants in the introduced range. Different ecological hypotheses have been invoked to explain the role of natural enemies in determining the success or failure of exotic plants (reviewed by Orians and Ward (2010)). For instance, the enemy release hypothesis predicts that exotic plants spread rapidly because they escape from their co-evolved natural enemies in the new range (Elton, 1958; Maron and Vilà, 2001). Accordingly, the evolution of increased competitive ability (EICA) hypothesis states that exotic plant species, with few specialized enemies in their new range, are more competitive than native species because they preferentially allocate resources to growth or reproduction instead of defences (Blossey and Nötzold, 1995). Although both hypotheses have been examined in a diverse array of terrestrial (Bossdorf et al., 2005; Joshi and Vrieling, 2005; Lombardero et al., 2008; Caño et al., 2009; Wang et al., 2012) and freshwater (Parker and Hay, 2005; Joshi and Tielbörger, 2012) systems, results from these studies are contrasting. The inconsistency in these observations may be due, in part, to variations in the extent to which herbivores cause effective pressure on host fitness in the introduced range.

Because the success of exotic plant species depends on phenotypic responses - either plastic or genetic - to the novel environment, plant invasions may be constrained by low genetic variation or low phenotypic plasticity for resistance traits (Orians and Ward, 2010; Inderjit, 2012). On the one hand, additive genetic variation in defensive traits is the fuel for the evolution of resistance against native herbivores in the introduced range. On the other hand, phenotypic plasticity is increasingly recognized as a potential mechanism determining invasiveness of exotic species (Alpert et al., 2000, Bossdorf et al., 2005). A highly plastic species may maintain high fitness across wide geographic ranges in the introduced locations by adjusting its phenotype according to local environmental conditions (Alpert and Simms, 2002). In other words, the success of exotic plants may be the result of the plastic responses of particular genotypes to different environmental conditions. Plasticity regarding the biotic environment (that is, induced resistance) could thus have a central role during plant invasions within an evolutionary context.

\footnotetext{
${ }^{1}$ Department of Ecology and Evolutionary Biology, University of California, Irvine, CA, USA; ${ }^{2}$ Misión Biológica de Galicia (MBG-CSIC), Apdo. 28, Pontevedra, Galicia, Spain and ${ }^{3}$ Centro de Investigación Forestal de Lourizán - Unidad Asociada MBG-CSIC, Apdo. 127, Pontevedra, Galicia, Spain

Correspondence: Dr X Moreira, Department of Ecology and Evolutionary Biology, University of California, Irvine, CA 92697, USA.

E-mail: xmoreira@mbg.csic.es
}

Received 15 June 2012; revised 30 October 2012; accepted 5 November 2012; published online 12 December 2012 
Despite the apparent logic of these predictions, few empirical studies have tested them and very little attention has been paid to separate genetic variation for constitutive and inducible expression of resistance in exotic plants (but see Wang et al. (2012)).

Assuming that the production of plant defences is costly in terms of growth and fitness, current theories on the evolution of plant resistance predict the existence of evolutionary trade-offs (negative genetic correlations) between resistance and fitness traits (Messina et al., 2002; Donaldson et al., 2006; Sampedro et al., 2011a), and between different resistance traits (reviewed by Koricheva et al. (2004)). The existence of these trade-offs may severely constrain the invasion success of plant populations in non-indigenous habitats, as trade-offs limit the simultaneous change of negatively correlated traits (Orians and Ward, 2010). However, the existing literature provides very little information on this subject.

Monterrey pine (Pinus radiata D. Don, Pinales: Pinaceae) is a longlived pine species native to five small areas in the central coast of California, that has become one of the most widely planted commercial timber trees in the world, mainly because of its fast growth rate and the quality of its wood. Several breeding programs focused on improving growth and timber quality have been developed in a number of countries, both in the Southern and Northern Hemisphere. In the Southern Hemisphere, this pine tree is considered a dangerous and invasive species, especially in New Zealand, Australia, South Africa and Chile (Lavery and Mead, 1998). In Southwestern Europe, however, where it is the most abundant exotic pine species (particularly in the Iberian Peninsula where it occupies more than 200000 ha), $P$. radiata does not show invasive behaviour, but coexists with other native pine species (Carrillo-Gavilan and Vila, 2010). Several field studies have shown that native generalist herbivores cause greater damage and mortality in this exotic pine species than in native congeners in the same study area (Lombardero et al., 2008; Zas et al., 2011), suggesting that herbivore susceptibility may be an underlying factor limiting the species' ability to invade new habitats. In previous work, for example, we found that the native pine species $P$. pinaster and the exotic $P$. radiata markedly differ in their responses to the native insect herbivore Hylobius abietis (Zas et al., 2011). Specifically, the exotic $P$. radiata showed a lower inducibility of defences and tolerance in response to herbivore damage than the native $P$. pinaster, and this may be an underlying mechanism that limits the former's ability to outcompete native species and colonize new habitats. However, a comprehensive assessment of the magnitude of genetic variation for constitutive and induced resistance and growth-defence trade-offs is currently lacking for this species, and this represents a fundamental gap in knowledge that constrains our understanding on how resistance may evolve and ultimately determine the invasion success of $P$. radiata.

In this paper, we (i) examine genetic variation in constitutive and induced chemical defences and resistance to two major native generalist herbivores in introduced populations of $P$. radiata in Spain, as possible constraints for the success of this exotic species outside of its natural range. We also examined additive genetic variation for the inducibility of these defence/resistance traits, that is, the difference between induced and constitutive conditions. Moreover, we tested for evolutionary trade-offs (ii) between growth and resistance traits, and (iii) between different resistance traits. To achieve these objectives, we conducted a greenhouse experiment with 34 half-sib families belonging to a Spanish breeding programme population selected for growth and stem form within established plantations in the area. We mimicked herbivore-induced responses using methyl jasmonate (MJ), a phytohormone that elicits defensive responses similar to those induced by herbivore attacks in young conifer trees (reviewed by Moreira et al. (2012b)). We quantified two defensive traits: nonvolatile resin in the stem (especially important for defence against phloem feeders) and total polyphenolics in the needles (especially important for defence against defoliators). Both defensive traits have been proved useful for identifying differences in resistance among pine families in previous studies (Sampedro et al., 2011a,b). We also evaluated pine resistance to two native insect herbivores through in vitro feeding tests using the large pine weevil $H$. abietis $\mathrm{L}$. (Coleoptera: Curculionidae), a phloem feeder that causes severe damage and high mortality in young conifer plantations in Europe (Zas et al., 2008), and the pine processionary caterpillar Thaumetopoea pityocampa Dennis and Schiff (Lepidoptera: Thaumetopoeidae), a defoliator that is regarded as a major pest of Mediterranean pine forests causing growth losses and leading to mortality after severe defoliation events (Hódar et al., 2003).

\section{MATERIALS AND METHODS}

\section{Plant material and experimental design}

We carried out a controlled greenhouse experiment following a randomized split-plot design replicated in four blocks, with MJ induction of defensive responses (two levels: MJ treatment and control) as the whole factor, and pine families (open-pollinated maternal half-sib families) as the split factor. Both treatments and families were randomly distributed within each block and whole plot, respectively (Littell et al., 2006). In total, there were 272 pine juveniles, corresponding to 4 blocks $\times 2 \mathrm{MJ}$ treatments $\times 34$ pine families.

$P$. radiata half-sib seeds were randomly selected from an $\mathrm{F}_{0}$ Galician breeding population planted in a clonal seed orchard used for seed production (Xunta de Galicia; Sergude, $42.82^{\circ} \mathrm{N}, 8.45^{\circ} \mathrm{W}$; northwestern Spain). The mother genotypes represented in the seed orchard come from a phenotypic mass selection of plus trees carried out in the early $1990 \mathrm{~s}$ by the Xunta de Galicia's Forestry Department, from plantations in northern Spain. All these plantations have been established with seeds collected in other $P$. radiata stands in the area, where this pine species has been intensively planted since its introduction in 1840s. The seed orchard contains a total of 58 unrelated genotypes selected on their phenotypic superiority for timber production (mainly superior growth and stem form), and clonally replicated by grafting. For the present study, we randomly selected a subsample of 34 out of the 58 open-pollinated pine families available in the seed orchard. The climate at the seed orchard is temperate humid Atlantic, with annual precipitation of about $1500 \mathrm{~mm}$ and mean annual temperatures of $11^{\circ} \mathrm{C}$, ranging typically between $25^{\circ} \mathrm{C}$ and $4{ }^{\circ} \mathrm{C}$ (maximum and minimum daily means, respectively). Soils in this region are typically thin, sandy and acidic, with high organic matter content, high total nitrogen content and very low concentration of available phosphorus.

On 15 April 2006, open-pollinated seeds from 34 P. radiata mother trees (our half-sib pine families) were individually sown in 2-L pots filled with peat and perlite $(1: 1 \mathrm{vol}: \mathrm{vol})$, fertilized with $12 \mathrm{~g}$ of a slow release fertilizer (Multicote N:P:K 15:15:15), and grown with natural light conditions and daily water irrigation following the commercial growth conditions in the facilities of TRAGSA Maceda forest nurseries $\left(42.16^{\circ} \mathrm{N} 7.39^{\circ} \mathrm{W}\right.$; northwestern Spain).

On 5 August 2008, approximately 2 years after being sown, half of the plants of each family were treated with a solution of $25 \mathrm{~mm}$ MJ (Sigma-Aldrich, St Louis, MO, USA, no. 39270-7) in deionized water with ethanol $2.5 \%$ (vol:vol). The remaining plants were treated only with the carrier solution, acting as control. Each plant received $4.5 \pm 0.5 \mathrm{ml}$ of solution applied to the foliage with a handheld sprayer to runoff. MJ dose and concentration were determined based on previous studies where we observed that exogenous application of $\mathrm{MJ}$ and real herbivory increased the concentration of resin in the stem and total phenolics in the needles by equivalent magnitudes (Moreira et al., 2009, 2012c). To avoid cross-contamination, the MJ treatment was applied in a separate greenhouse chamber where plants remained for a $24-\mathrm{h}$ period to allow drying of the solution. 


\section{Sampling and measurements}

On 27 August 2008, 3 weeks after MJ application, we measured plant height and stem basal diameter, and all pine juveniles were harvested. Immediately after harvesting, a fresh 10-cm-long segment of the lowest part of the stem of each plant was sampled, weighed, immediately frozen and preserved at $-30{ }^{\circ} \mathrm{C}$ for analysis of non-volatile resin content. A subsample of needles $(\sim 2 \mathrm{~g})$ was immediately weighed, oven-dried $\left(45^{\circ} \mathrm{C}\right.$ to constant weight) and then manually ground in a mortar with liquid nitrogen for analyses of total phenolic compounds.

\section{Chemical analysis}

Total phenolics in the needles were extracted and analysed as described by Moreira et al. (2012a). Briefly, phenolics were extracted from $300 \mathrm{mg}$ of plant tissue with aqueous methanol (1:1 vol:vol) in an ultrasonic bath for $15 \mathrm{~min}$, followed by centrifugation and subsequent dilution of the methanolic extract. Total phenolic content was determined colorimetrically by the Folin-Ciocalteu method in a Biorad 650 microplate reader (Bio-Rad Laboratories Inc., Philadelphia, PA, USA) at $740 \mathrm{~nm}$, using tannic acid as standard, and referred to the vegetal tissue in a dried weight (d.w.) basis.

Concentration of non-volatile resin in the stem was estimated gravimetrically (Sampedro et al., 2011a) and expressed as $\mathrm{mg}$ of non-volatile resin $\mathrm{g}^{-1}$ stem d.w. Subsequently, about $5 \mathrm{~g}$ fresh weight of stem material was transferred into preweighed borosilicate test tubes, resin was extracted with $3 \mathrm{ml}$ of hexane $\left(15 \mathrm{~min}\right.$ at $20^{\circ} \mathrm{C}$ in an ultrasonic bath and then for $24 \mathrm{~h}$ at room temperature), the extract was filtered (Whatman GFF, Whatman Int. Ltd, Maidstone, Kent, UK) into new preweighed test tubes, and the entire extraction step was then repeated again. The solvent in the tubes was evaporated to dryness and the mass of the non-volatile resin residue was determined at the nearest $0.0001 \mathrm{~g}$. This gravimetric determination of non-volatile resin was highly correlated with the concentration of the diterpenoid fraction $(r=0.9214 ; P=0.00002)$, as quantified by gas chromatography in previous trials (Sampedro et al., 2011a).

\section{Herbivore-feeding trials}

Immediately after plant harvesting, two independent in vitro feeding tests were used to evaluate the effect of the application of MJ and genetic variation on resistance against the large pine weevil $H$. abietis and the pine processionary T. pityocampa. In the $H$. abietis feeding test, two 2.5 -cm-long twigs of fresh basal stem of each juvenile were deposited on moistened filter paper in $11 \mathrm{~cm}$ diameter plastic Petri dishes $(n=272)$, and offered to one weevil for $48 \mathrm{~h}$ in darkness (Carrillo-Gavilán et al., 2012). After this time, we measured the percentage of gnawed area of each stem piece by digital image analysis with the program Image Pro Plus. For the T. pityocampa feeding test, a group of $\sim 20$ young needles from each plant belonging to 14 of our 34 open-pollinated families were deposited on moistened filter paper in polyethylene containers, and offered to preweighed groups of 10 second-instar larvae for 5 days (Carrillo-Gavilán et al., 2012). After this time, we estimated the dry weight of needles (in $\mathrm{mg}$ ) consumed by the larvae through the difference between initial and final needle weight, adjusted by the water content of each sample (CarrilloGavilán et al., 2012). The total number of dishes in this bioassay was 112. Adult pine weevils and pine processionary caterpillar nests had been previously collected in June 2008 from P. pinaster stands at Cuspedriños (Galicia, Spain, $42.30^{\circ} \mathrm{N} ; 8.30^{\circ} \mathrm{W}$ ) and Arousa Island (Galicia, Spain, $42.33^{\circ} \mathrm{N} ; 8.51^{\circ} \mathrm{W}$ ), respectively. Although performing this kind of in vitro bioassay instead of in vivo feeding trials alters the natural environment for feeding, it reduces the bias in the interpretation of the results given that even short exposure times of pine trees to in vivo insect feeding may elicit induced responses that could negatively interfere in the interpretation of the results (Sampedro et al., 2011b).

\section{Statistical analyses}

Plant growth, chemical defences and resistance were analysed by fitting mixed models with the induction treatment $(\mathrm{T})$ as a fixed factor and the families $(\mathrm{F})$, the blocks (B) and the $\mathrm{F} \times \mathrm{T}$ and $\mathrm{B} \times \mathrm{T}$ interactions as random factors. Restricted maximum likelihood analysis was used to estimate variance components and to statistically test for causes of family $\times$ treatment interaction, that is, genetic variation in inducibility. We followed a likelihood-based approach similar to that used in crop sciences for the analysis of the genotype $\times$ environment interaction in multi-environment variety trials (Yang, 2002; de la Mata and Zas, 2010). Briefly, we first fitted a full mixed model that allowed for heterogeneity of family and residual variances across treatments and a family covariance between them. Then, by constraining different elements of the family and residual covariance structures, we tested whether there was heterogeneity of residual and family variances, and whether the family correlation between both treatments deviated from a perfect correlation $\left(r_{\mathrm{G}}=1\right)$. This allowed us to properly determine and compare the genetic variation in constitutive and induced modes and to quantify the extent to which the induction treatment altered the variability of resistance traits. Hypothesis testing regarding the constraints imposed on the family and residual covariance structures was done by comparing the restricted loglikelihoods of the constrained model and the full model, where the difference in two times the log-likelihood of these models is distributed as a one-tailed $\chi^{2}$, with degrees of freedom given by the differences between the number of covariance parameters specifying the full model and the reduced model (Fry, 2004). The statistical significance of each specific variance component was also assessed using likelihood ratio tests by fitting reduced models in which we fixed the given (co)variance parameter to 0 . The mixed models were fitted with the MIXED procedure of SAS (Littell et al., 2006) accommodating the SAS programs used by Yang (2002) (see details in Supplementary Table S1 of Supplementary Material). The analyses of insect damage on the bioassays were carried out including the initial insect weight as a covariate in the mixed models.

Narrow-sense heritability $\left(h_{\mathrm{i}}^{2}\right)$ for each trait in constitutive and MJ-treated state was calculated as the ratio of additive genetic variance to total phenotypic variance within each treatment. Pine families were assumed to be true halfsibs, and thus the additive genetic variance was estimated as four times the family variance $\left(\sigma_{\mathrm{A}}^{2}=4 . \sigma_{\mathrm{F}}^{2}\right.$, where $\sigma_{\mathrm{F}}^{2}$ is the family variance). s.e. of heritability were estimated by the Delta method upon the asymptotic estimates of the variances and covariances of the variance components of the mixed model (Lynch and Walsh, 1998). The additive genetic coefficient of variation $\left(\mathrm{CV}_{\mathrm{A}}\right)$ in each mode was also calculated for each trait as the ratio between the additive genetic s.d. and the overall mean in each treatment.

Because resistance traits in induced plants results from the sum of preexisting constitutive levels plus the induced response, variability in the induced mode does not properly represent the variation in inducibility, that is in the ability to increase defences after induction. To test for genetic variation in inducibility per se among families, we further analysed our data using a bootstrap approximation, where inducibility of each induced plant was estimated as the difference between the value of the resistance trait for a given plant and that of the other four plants of the same family in the control treatment. This resulted in four estimates of inducibility for each induced plant, which were considered as repeated measures on the same subject. For the statistical analysis of this inducibility trait, we fitted a repeated measures mixed model, with family and family $\times$ constitutive-block as random factors.

Genetic correlations between pine growth, insect damage, and chemical defenses were estimated separately for the constitutive (control) and MJtreated treatments, using a multivariate restricted maximum likelihood estimation with SAS Proc MIXED according to Holland (2006). Bonferroni's correction was used to reduce the chances of obtaining false-positive results (type I errors) when multiple pairwise tests are performed on a single set of data (Dunn, 1961).

\section{RESULTS}

Genetic variation for pine growth, chemical defences and herbivore resistance

Primary growth showed significant genetic variation both in constitutive and induced states (Table 1). Total height varied up to 1.4-fold $(63.9-90.1 \mathrm{~cm})$ and 1.5 -fold $(57.0-87.5 \mathrm{~cm})$ among pine families in control and induced plants, respectively, showing moderate heritability in both cases (Table 2). Application of MJ significantly depressed primary growth (Table 1), with total height of the pine juveniles treated with $\mathrm{MJ}$ being $10 \%$ lower than that in control plants (Table 2). However, we found no significant effects of MJ application 
or plant family on secondary growth (Table 1). Although the reaction norms for height growth across the two treatments suggest genetic variation in the response to $\mathrm{MJ}$, the likelihood-based analyses only detected a marginally significant deviation from perfect correlation between control and MJ-treated conditions (Figure 1a). Accordingly, the reduction of height after $\mathrm{MJ}$ application showed just moderate heritability estimates with quite large s.e. (Table 2).

The constitutive concentrations of stem non-volatile resin and needle total phenolics varied from $14.1-21.8 \mathrm{mgg}^{-1}$ d.w. and from 24.2-43.0 $\mathrm{mg} \mathrm{g}^{-1}$ d.w., respectively, among pine families. We found significant family control of the constitutive concentration of stem non-volatile resin (Table 3), with high narrow-sense heritability (Table 2), but no genetic variation was found in induced plants (Table 3). In contrast, total needle phenolics varied significantly among pine families only after MJ induction (Table 3), with a moderate heritability estimate (Table 2). Both the concentration of stem non-volatile resin and needle total phenolics significantly increased after MJ application, being $17 \%$ and $15 \%$ greater in treated plants than those in control plants, respectively (Table 2). Inducibility of stem non-volatile resin significantly varied among families as revealed by the significant $\mathrm{F} \times \mathrm{T}$ interaction, which was mainly due to the significant differences in family variances between treatments

Table 1 Summary of the full mixed models for growth of 34 $P$. radiata open-pollinated families in constitutive and MJ-treated conditions 15 days after MJ application

\begin{tabular}{|c|c|c|c|c|c|c|}
\hline \multirow[t]{2}{*}{ Fixed effects } & \multicolumn{3}{|c|}{ Height } & \multicolumn{3}{|c|}{ Diameter } \\
\hline & $d f$ & $\mathrm{~F}$ & $\mathrm{P}$-value & $d f$ & $\mathrm{~F}$ & P-value \\
\hline Induction treatment & 1,3 & 10.8 & 0.046 & 1,3 & 1.5 & 0.312 \\
\hline Random effects & Varcomp & $\chi^{2}$ & $\mathrm{P}$-value & Varcomp & $\chi^{2}$ & P-value \\
\hline $\begin{array}{l}\text { Family (in control) } \\
\text { Family (in induced) } \\
\text { Correlation control-induced } \\
\text { Residual (control) } \\
\text { Residual (induced) }\end{array}$ & $\begin{array}{r}19.5 \pm 13.4 \\
20.5 \pm 12.6 \\
0.40 \pm 0.40 \\
126.9 \pm 17.8 \\
108.7 \pm 15.4\end{array}$ & $\begin{array}{l}3.8 \\
4.8 \\
0.8\end{array}$ & $\begin{array}{l}0.026 \\
0.014 \\
0.186\end{array}$ & $\begin{array}{l}0.02 \pm 0.05 \\
0.01 \pm 0.04 \\
1.00 \pm 0.00 \\
1.10 \pm 0.14 \\
0.88 \pm 0.11\end{array}$ & $\begin{array}{l}0.1 \\
0.1 \\
0.1\end{array}$ & $\begin{array}{l}0.376 \\
0.376 \\
0.376\end{array}$ \\
\hline
\end{tabular}

Abbreviations: df, degree of freedom; MJ, methyl jasmonate.

The treatment of defence induction $(\mathrm{T})$ is a fixed effect, and the $F$ values and corresponding $\mathrm{df}$ are shown. The full mixed model assumed a completely unstructured (co)variance structure for the family random factor and heterogeneous residual variances across treatments. Variance component estimates $( \pm$ s.e. $)$ and the likelihood ratio tests $\left(\chi^{2}\right)$ testing whether they are significantly greater than zero are shown. Significant $P$-values $(P<0.05)$ are typed in bold.
(Figure $1 \mathrm{~b}$ ) as revealed by the likelihood ratio tests. The heritability estimate of the inducibility of stem non-volatile resin was very high (Table 2). For needle phenolics, the $\mathrm{F} \times \mathrm{T}$ interaction was nonsignificant, and the likelihood-based analysis did not detect significant differences in family variance between treatments or ranking changes in the reaction norm (no deviations from perfect correlation in Figure 1c). However, the family variance for total needle phenolics was only significantly greater than zero after MJ induction (Table 3, Figure 1c). Consistently, heritability estimate for the inducibility of needle phenolics was only moderate and showed very large s.e. (Table 2).

Induced plants showed increased resistance to $H$. abietis in the in vitro bioassays, as the pine weevils consumed $20 \%$ less phloem in the MJ-treated plants than in the control plants (Table 2). However, we did not detect significant variation among pine families in the weevil damage, either in constitutive or in induced mode (Table 4). Ingestion of needles by the pine processionary caterpillars was also significantly affected by the induction treatment (Table 4). Larvae consumed $10 \%$ less needles in the MJ-treated plants than in control plants (Table 2). Processionary damage in constitutive plants significantly differed among pine families, but this genetic variation disappeared after MJ induction (Table 4). Heritability of processionary damage in constitutive plants was very high but also showed large s.e. (Table 2). The likelihood-based analysis indicated significant genetic variation in the intensity of damage after treatment with $\mathrm{M}$ ) (significant $\mathrm{F} \times \mathrm{T}$ interaction), which was caused mainly by differences in family variance in constitutive and induced states (Figure 1d). Consistently, heritability of the reduction of damage due to the induction of defences was very high, but again with large s.e. (Table 2).

\section{Genetic correlations between growth, herbivore damage and chemical defences}

We did not find significant genetic correlations between plant growth (height and diameter) and chemical defenses (stem non-volatile resin and needle total phenolics), either in constitutive or in MJ-treated conditions (Table 5, Supplementary Figure S1), suggesting that the production of chemical defences was not costly in terms of growth for our experimental seedlings. In analysing trade-offs between different defensive traits, we did not find significant genetic correlations between the production of non-volatile resin in the stem and total phenolics in the needles, either in constitutive or in MJ-treated conditions (Table 5, Supplementary Figure S1).

Table 2 Mean ( \pm s.e.), $\mathrm{CV}_{\mathrm{A}}$ and $h_{\mathrm{i}}^{2}$ estimates ( \pm s.e.) for different traits assessed in control (constitutive) and MJ-treated (induced) seedlings of $P$. radiata

\begin{tabular}{|c|c|c|c|c|c|c|c|}
\hline \multirow[t]{2}{*}{ Trait } & \multicolumn{3}{|c|}{ Constitutive } & \multicolumn{3}{|c|}{ Induced } & \multirow{2}{*}{$\frac{\text { Inducibility }}{\mathrm{h}_{i}^{2}}$} \\
\hline & Mean & $C V_{A}$ & $\mathrm{~h}_{i}^{2}$ & Mean & $C V_{A}$ & $\mathrm{~h}_{i}^{2}$ & \\
\hline Height $(\mathrm{cm})$ & $76.4 \pm 1.0$ & 11.5 & $0.53 \pm 0.14$ & $71.2 \pm 1.0$ & 12.6 & $0.62 \pm 0.18$ & $0.66 \pm 0.48$ \\
\hline Diameter (mm) & $6.94 \pm 0.09$ & 3.6 & $0.06 \pm 0.03$ & $6.79 \pm 0.08$ & 3.4 & $0.06 \pm 0.04$ & - \\
\hline Non-volatile resin $\left(\mathrm{mgg}^{-1}\right)$ & $16.6 \pm 0.5$ & 79.3 & $0.91 \pm 0.20$ & $19.8 \pm 0.4$ & 36.2 & $0.28 \pm 0.44$ & $1.03 \pm 0.47$ \\
\hline Total phenolics $\left(\mathrm{mgg}^{-1}\right)$ & $32.1 \pm 0.9$ & 13.9 & $0.18 \pm 0.11$ & $37.3 \pm 1.0$ & 21.6 & $0.47 \pm 0.08$ & $0.22 \pm 0.61$ \\
\hline Damage by $H$. abietis $\left(\mathrm{mm}^{2}\right)$ & $21.9 \pm 0.8$ & 0.0 & - & $18.0 \pm 0.8$ & 0.0 & - & - \\
\hline Damage by $T$. pytiocampa (mg) & $3.48 \pm 0.19$ & 24.5 & $2.04 \pm 1.29$ & $2.52 \pm 0.1$ & 14.1 & $0.58 \pm 1.47$ & $1.43 \pm 0.44$ \\
\hline
\end{tabular}

Abbreviations: $\mathrm{CV}_{\mathrm{A}}$, additive genetic coefficient of variation; $h_{\mathrm{i}}{ }^{2}$, individual heritability; $\mathrm{MJ}$, methyl jasmonate.

Heritability estimates of the plastic changes after MJ induction (inducibility) are also shown for those traits with significant family variation. 
a

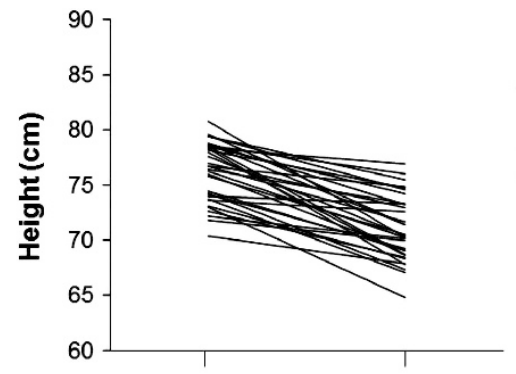

b

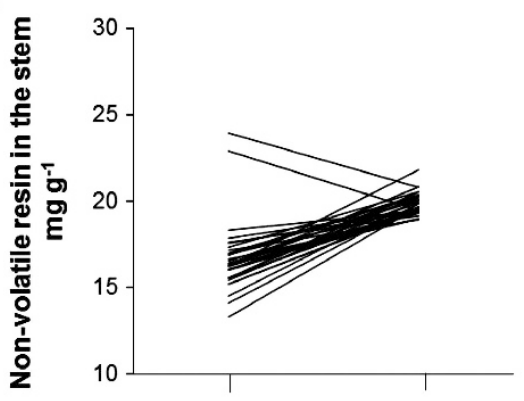

C

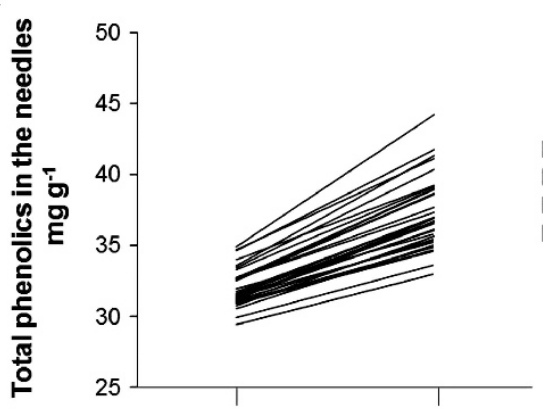

d

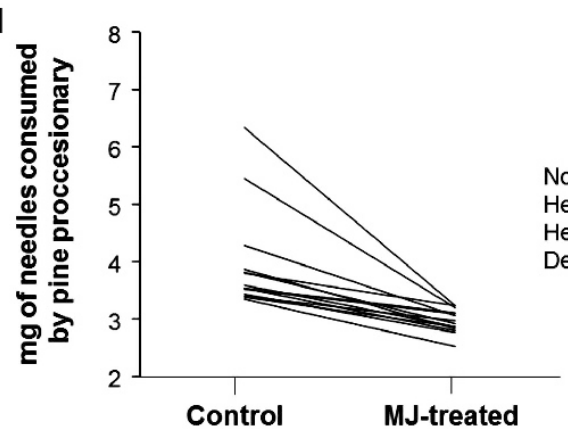

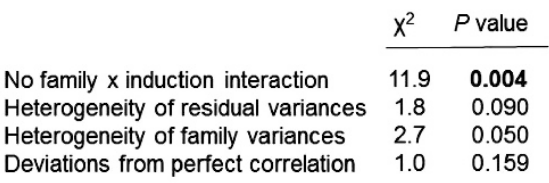

\begin{tabular}{lcc} 
& $X^{2}$ & $P$ value \\
\cline { 2 - 3 } No family $\mathrm{x}$ induction interaction & 1.7 & 0.318 \\
Heterogeneity of residual variances & 0.4 & 0.264 \\
Heterogeneity of family variances & 0.5 & 0.240 \\
Deviations from perfect correlation & 0.0 & 0.500
\end{tabular}

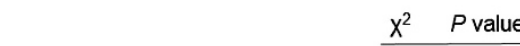

Namily $\mathrm{x}$ induction interaction $\quad \begin{array}{lll}7.3 & \mathbf{0 . 0 3 1}\end{array}$ Heterogeneity of residual variances $1.2 \quad 0.137$ Heterogeneity of family variances $\quad 2.5 \quad 0.057$ Deviations from perfect correlation $\quad 0.8 \quad 0.186$

Figure 1 Norms of reaction for (a) height, (b) concentration of stem non-volatile resin, (c) concentration of needle total phenolics and (d) milligrams of needles consumed by T. pityocampa larvae in the in vitro feeding trial. Each line represents the mean response $(n=4$ replicates) of a single pine half-sib family in the control versus MJ-treated conditions. Likelihood ratios and $P$-values for testing different hypotheses on the relevance and interpretation of the genotype by treatment interaction are also shown (see details in Supplementary Table S1 of Supplementary Materials). Significant $P$-values $(P<0.05)$ are typed in bold.

We did not find significant genetic correlations between plant growth and effective resistance against the two herbivores (Table 5, Supplementary Figure S1). Interestingly, we found a positive genetic correlation between $H$. abietis and T. pityocampa damage under constitutive conditions (Table 5, Supplementary Figure S1), indicating cross-resistance, in that pine families which were more resistant to $H$. abietis damage were also more resistant to T. pityocampa damage. This genetic correlation was not significant after MJ application.

\section{DISCUSSION}

P. radiata has been extensively cultivated as a timber species in many temperate parts of the world during the last century. In some areas of the southern hemisphere, it is considered an aggressive and invasive species that displaces native trees (Lavery and Mead, 1998). However, despite repeated introductions, $P$. radiata has not invaded Europe (Carrillo-Gavilan and Vila, 2010) and currently coexists with other native pine species without evidence of spreading outside of the 
Table 3 Summary of the full mixed models for chemical defences of $34 P$. radiata open-pollinated families in constitutive and $\mathrm{MJ}$-treated conditions 15 days after MJ application

\begin{tabular}{|c|c|c|c|c|c|c|}
\hline \multirow[t]{2}{*}{ Fixed effects } & \multicolumn{3}{|c|}{ Non-volatile resin } & \multicolumn{3}{|c|}{ Total phenolics } \\
\hline & $d f$ & $\mathrm{~F}$ & $\mathrm{P}$-value & $d f$ & $\mathrm{~F}$ & P-value \\
\hline Induction treatment & 1,3 & 17.4 & 0.025 & 1,3 & 13.7 & 0.034 \\
\hline Random effects & Varcomp & $\chi^{2}$ & P-value & Varcomp & $\chi^{2}$ & P-value \\
\hline $\begin{array}{l}\text { Family (in control) } \\
\text { Family (in induced) } \\
\text { Correlation control-induced } \\
\text { Residual (control) } \\
\text { Residual (induced) }\end{array}$ & $\begin{array}{r}7.6 \pm 3.6 \\
1.6 \pm 1.8 \\
0.04 \pm 0.5 \\
25.8 \pm 3.6 \\
19.7 \pm 2.8\end{array}$ & $\begin{array}{l}8.4 \\
1.0 \\
0\end{array}$ & $\begin{array}{l}0.002 \\
0.159 \\
0.500\end{array}$ & $\begin{array}{r}5.8 \pm 9.4 \\
16.6 \pm 12.6 \\
0.76 \pm 0.84 \\
105.6 \pm 15.5 \\
120.7 \pm 17.6\end{array}$ & $\begin{array}{l}1.4 \\
3.4 \\
1.0\end{array}$ & $\begin{array}{l}0.118 \\
0.033 \\
0.159\end{array}$ \\
\hline
\end{tabular}

Abbreviations: df, degree of freedom; MJ, methyl jasmonate.

The treatment of defence induction $(\mathrm{T})$ is a fixed effect, and the $F$ values and corresponding df are shown. The full mixed model assumed a completely unstructured (co)variance structure for the family random factor, and heterogeneous residual variances across treatments. Variance component estimates $( \pm$ s.e. $)$ and the likelihood ratio tests $\left(\chi^{2}\right)$ testing whether they are significantly greater than zero are shown. Significant $P$-values $(P<0.05)$ are typed in bold.

Table 4 Summary of the full mixed models for the evaluation of Hylobius abietis and Thaumetopoea pityocampa damage through in vitro feeding tests

\begin{tabular}{|c|c|c|c|c|c|c|}
\hline \multirow[t]{2}{*}{ Fixed effects } & \multicolumn{3}{|c|}{ Damage by $\mathrm{H}$. abietis } & \multicolumn{3}{|c|}{ Damage by T. pityocampa } \\
\hline & $d f$ & $\mathrm{~F}$ & P-value & $d f$ & $\mathrm{~F}$ & P-value \\
\hline Induction treatment & 1,3 & 13.6 & 0.035 & 1,3 & 12.8 & 0.038 \\
\hline Insect weight & 1,193 & 28.3 & $<0.001$ & 1,73 & 4.1 & 0.048 \\
\hline Random effects & Varcomp & $\chi^{2}$ & P-value & Varcomp & $\chi^{2}$ & P-value \\
\hline $\begin{array}{l}\text { Family (in control) } \\
\text { Family (in induced) } \\
\text { Correlation control-induced } \\
\text { Residual (control) } \\
\text { Residual (induced) }\end{array}$ & $\begin{array}{c}0 \pm 0 \\
0 \pm 0 \\
1 \pm 0 \\
0.15 \pm 0.02 \\
0.21 \pm 0.03\end{array}$ & $\begin{array}{l}0.0 \\
0.0 \\
0.0\end{array}$ & $\begin{array}{l}0.500 \\
0.500 \\
0.500\end{array}$ & $\begin{array}{l}0.032 \pm 0.016 \\
0.008 \pm 0.008 \\
0.500 \pm 0.45 \\
0.032 \pm 0.008 \\
0.043 \pm 0.01\end{array}$ & $\begin{array}{r}14.9 \\
2.5 \\
1.0\end{array}$ & $\begin{array}{l}0.000 \\
0.057 \\
0.159\end{array}$ \\
\hline
\end{tabular}

Abbreviations: df, degree of freedom; MJ, methyl jasmonate.

The experiment was conducted with several $P$. radiata open-pollinated families ( 34 for $H$. abietis test and 14 for T. pityocampa test) in constitutive and MJ-treated conditions 15 days after MJ application. The treatment of defence induction (T) is a fixed effect, and the $F$ values and corresponding df are shown. Insect weight was included as covariate. The full mixed model assumed a completely unstructured (co)variance structure for the family random factor, and heterogeneous residual variances across treatments. Variance component estimates ( \pm s.e.) and the likelihood ratio tests $\left(\chi^{2}\right)$ testing whether they are significantly greater than zero are shown. Significant $P$-values $(P<0.05)$ are typed in bold.

planting sites. The failure of invasions by alien pines in Europe has been suggested to be related to the occurrence of native pine congeners supporting native herbivores, which may easily recognize the exotic plants as food sources (Carrillo-Gavilan and Vila, 2010). In this sense, several authors have introduced the concept of 'biotic resistance', that is, the ability of resident species in a community to inhibit the establishment and invasion of an introduced species (see meta-analysis by Levine et al. (2004)). Supporting this hypothesis, $P$. radiata has shown reduced tolerance and reduced ability for expressing induced resistance to native herbivores when compared with the native pine congener Maritime pine (Zas et al., 2011). Other factors that constrain the evolution of resistance against native herbivores, such as lack of genetic variation in resistance and tradeoffs between relevant life history traits, have also been suggested as explanations for the failure of biological invasions by alien plants (Orians and Ward, 2010), but these are yet to be substantiated.
Our findings indicate few major genetic constraints on the evolution of resistance against native herbivores in the exotic pine species $P$. radiata, and three of our results are particularly noteworthy in this respect. First, we found significant genetic variation for the production of constitutive and/or induced chemical defences and resistance against pine processionary, with moderate-to-high heritabilities for these resistance traits. Second, we found no evolutionary trade-offs between plant defence/resistance and growth traits, or between different defence traits. Finally, we found cross-resistance against the two native herbivores assayed in this study. Altogether our results indicate that the introduced population of $P$. radiata has limited genetic constraints that impede the evolution of resistance as a response to the pressure imposed by native herbivores.

Adaptive evolution is considered one of the key mechanisms enabling the success of exotic plants in their new range (Maron et al., 2004). Given that the absence of genetic variation constrains evolution, low levels of genetic variation for resistance against herbivores that are native to the introduced range may influence plant-antagonist dynamics of exotic plant species outside their natural range. As pointed out by Orians and Ward (2010) and Inderjit (2012), constraints on the evolution of defence/resistance traits do not appear to be more common in exotic species, but few experiments have tested this hypothesis (Oduor et al., 2011). Moreover, there is an important gap in knowledge regarding genetic variation for induced defences in exotic plant species (Cipollini et al., 2005; Eigenbrode et al., 2008; Wang et al., 2012). As there is increasing evidence that plants respond to herbivory damage with highly specific responses (Bingham and Agrawal, 2010; Karban, 2011), it is reasonable to argue that inducibility of defences in exotic species may vary inside versus outside of their native range based on differences in the identity and number of herbivore species consuming the plant in each area. However, our results indicate significant genetic variation for constitutive levels and/or inducibility in most of defence/resistancestudied traits within the introduced population, suggesting a lack of genetic constraints for the evolution of defence/resistance traits in this exotic pine species outside its natural range. Interestingly, we found additive genetic variation for inducibility of non-volatile resin in stems and resistance to the pine processionary, and large differences in the family variance after induction with MJ for almost all defensive traits, suggesting enough variability to evolve according to the selection pressure imposed by the native herbivores.

Our results indicated additive genetic variation for both constitutive levels and/or inducibility of both resistance traits; however, general conclusions drawn from this trend should be made with caution when using experimental induction treatments. Indeed, responses to specific herbivore species may differ from those observed due to chemical elicitors (Zas et al., 2011). On the other hand, the lack of genetic variation in the effective resistance to the pine weevil contradicts the results observed at field conditions, in which the same $P$. radiata population showed large genetic variation in susceptibility to this insect (Zas et al., 2008). Performing in vitro bioassays such as those used in the present study impede the ability of responding to the damage caused by the insect, and this may alter the expression of the overall resistance potential within the studied population (Zas et al., 2011). Finally, the relatively small sample size used in the bioassays may also be hampering the detection of significant genetic effects, and is probably responsible for the high s.e. estimates of heritability in resistance.

Our study failed to detect evolutionary trade-offs between plant defence/resistance traits and growth. Although the emergence of this type of cost-related trade-offs has been shown to be context 
Table 5 Restricted maximum likelihood estimates of genetic correlation (s.e.) between traits of growth, concentration of quantitative chemical defenses and effective herbivore resistance in bioassays of Pinus radiata juveniles in constitutive (above diagonal) and MJ-treated (below diagonal) conditions

\begin{tabular}{|c|c|c|c|c|c|c|}
\hline & \multicolumn{2}{|c|}{ Growth } & \multicolumn{2}{|c|}{ Defences } & \multicolumn{2}{|c|}{ Effective resistance } \\
\hline & Height & Diameter & $\begin{array}{c}\text { Non-volatile resin in } \\
\text { the stem }\end{array}$ & $\begin{array}{c}\text { Total phenolics in the } \\
\text { needles }\end{array}$ & $\begin{array}{c}\text { Damage by Hylobius } \\
\text { abietis }\end{array}$ & $\begin{array}{c}\text { Damage by Thaumetopoea } \\
\text { pityocampa }\end{array}$ \\
\hline Height & - & $0.562(0.001)$ & $0.144(0.416)$ & $-0.096(0.589)$ & $0.068(0.702)$ & $0.214(0.462)$ \\
\hline Diameter & $0.379(0.027)$ & - & $-0.219(0.213)$ & $0.118(0.287)$ & $-0.429(0.011)$ & $0.060(0.838)$ \\
\hline Non-volatile resin in the stems & $-0.138(0.436)$ & $-0.184(0.297)$ & - & $-0.114(0.520)$ & $-0.421(0.013)$ & $0.171(0.559)$ \\
\hline Total phenolics in the needles & $0.245(0.162)$ & $0.089(0.617)$ & $0.062(0.727)$ & - & $-0.039(0.827)$ & $0.388(0.170)$ \\
\hline Damage by $H$. abietis & $0.216(0.220)$ & $0.104(0.558)$ & $0.158(0.372)$ & $0.062(0.727)$ & - & $0.689(0.006)$ \\
\hline Damage by $T$. pityocampa & $0.352(0.217)$ & $0.215(0.460)$ & $0.086(0.770)$ & $0.224(0.441)$ & $0.231(0.427)$ & - \\
\hline
\end{tabular}

Abbreviation: MJ, methyl jasmonate.

Bonferroni's correction for multiple comparisons was applied by dividing the critical $P$-value $(\alpha=0.05)$ by the number of comparisons being made ( $n=6)$. Significant correlation estimates at $P<0.008$ are given in bold. $N=34$ open-pollinated families, except for damage by $T$. pytiocampa ( $N=14$ families).

dependent (Sampedro et al., 2011a), our results suggest no constraints for the independent evolution of these two functions in the studied population of this exotic pine species. The EICA hypothesis, one of the central tenets of invasion biology theory, predicts that exotic plant species suffer less damage by herbivores in their introduced ranges and they might thus reallocate fewer resources to defence and more to growth and reproduction. In addition to the differential herbivore pressures, this outcome arises because plant defence/resistance traits are energetically expensive to produce and maintain, and therefore it is commonly assumed that resistance and fitness traits trade-off with each other (Messina et al., 2002; Donaldson et al., 2006; Sampedro et al., 2011a). The existence of such trade-offs between defence and fitness traits may explain why exotic plant species are usually more vigorous in non-indigenous habitats (usually with reduced load of enemies) than in their natural range. However, in a 2010 review, Orians and Ward (2010) reported that only 12 out of 34 studies supported the full predictions of EICA. Thus, it would appear that EICA predictions do not fully explain the success of exotic plant species in their introduced range. Furthermore, the EICA hypothesis is probably less suitable for long-lived plants such as the pine studied here than for annual invasive species, as in trees the effects of selection against herbivore pressure are determined primarily by their long generation times (Lombardero et al., 2008; Zas et al., 2011).

Our results also showed a lack of evolutionary trade-offs between non-volatile resin and total phenolics, two of the most important anti-herbivore defences in conifer trees, evidencing no constraints on the independent evolution of both defensive traits in the exotic pine species $P$. radiata. As we explained above, the production and maintenance of chemical defences is assumed to be costly for plants when resources are limited. Therefore, the possession of multiple defensive mechanisms would severely compromise available resources for growth and reproduction. In this sense, many authors have reported the existence of evolutionary trade-offs among anti-herbivore resistance traits due to the costs of their production and/or redundant functions against herbivores (Rudgers et al., 2004; Wang et al., 2012). However, a convincing meta-analysis (Koricheva et al., 2004) proposed that plants may possess multiple defensive traits without excessive metabolic costs in particular situations, especially when the costs associated with the possession of multiple defensive traits are outweighed by their benefits. For example, the combined expression of multiple defensive traits may work to reduce herbivory and improve plant resistance to a large number of natural enemies more effectively than defensive traits that target individual herbivore species. The possession of multiple and generalist defensive mechanisms is especially relevant for long-lived trees that need to defend themselves against a wide array of herbivores (Mumm and Hilker, 2006). These different enemies are expected to exert diffuse selection pressures on pine trees, favouring the expression of multiple defence compounds, effective against multiple herbivores. This idea is consistent with our results that showed the pine families with high resistance to $H$. abietis also showed high resistance to $T$. pityocampa. Although the defensive traits measured in this study, quantitative resin and phenolics, have been commonly shown to confer resistance to a diverse array of herbivores associated with conifers (see review by Mumm and Hilker (2006)), further studies should address whether trade-offs between other defensive traits not assayed here, that is, individual terpenes and phenolics, proteins, alkaloids and anatomical defences, may be also involved in the success of this exotic pine species in non-indigenous habitats.

In summary, our results showed no evidence of major genetic constraints on the evolution of resistance against native herbivores in the exotic pine species $P$. radiata in a non-indigenous habitat. The existence of genetic variation for resistance traits and the lack of evolutionary trade-offs between growth and resistance traits may be key factors that promote rapid evolution of this exotic plant species in their introduced range. Altogether, our results suggest that this pine species has the potential to evolve in the introduced range according to the selection pressures imposed by the local enemies, and could become invasive in the future.

\section{DATA ARCHIVING}

Data deposited in the Dryad repository doi:10.5061/dryad.53bp0.

\section{CONFLICT OF INTEREST}

The authors declare no conflict of interest.

\section{ACKNOWLEDGEMENTS}

We thank Patricia Martíns, Sergio Piñeiro, Tamara Sotelo, Raúl de la Mata, María Clara Fernández and Yolanda Magdalena for their help in plant sampling, assessments and chemical analyses. Francisco J Lario is also acknowledged for his help with the nursery culture. Comments and suggestions by Kailen A Mooney, Jessica Pratt, Luis Abdala-Roberts, Will Petry and three anonymous reviewers helped to improve the manuscript. We are also very grateful for the exhaustive language editing by David Brown. This research 
was supported by AGL2010-18724 COMPROPIN grant. LS and XM received financial support from DOC-INIA and Postdoctoral Fulbright/Ministry of Education grant programs, respectively.

Alpert P, Bone E, Holzapfel C (2000). Invasiveness, invasibility and the role of environmental stress in the spread of non-native plants. Perspect Plant Ecol Evol Syst 3: 52-66.

Alpert P, Simms EL (2002). The relative advantages of plasticity and fixity in different environments: when is it good for a plant to adjust? Evol Ecol 16: 285-297.

Bingham RA, Agrawal AA (2010). Specificity and trade-offs in the induced plant defence of common milkweed Asclepias syriaca to two lepidopteran herbivores. J Ecol 98 1014-1022.

Blossey B, Nötzold R (1995). Evolution of increased competitive ability in invasive nonindigenous plants: a hypothesis. J Eco/ 83: 887-889.

Bossdorf O, Auge H, Lafuma L, Rogers WE, Siemann E, Prati D (2005). Phenotypic and genetic differentiation between native and introduced plant populations. Oecologia 144: $1-11$.

Carrillo-Gavilan A, Vila M (2010). Little evidence of invasion by alien conifers in Europe. Divers Distrib 16: 203-213.

Carrillo-Gavilán A, Moreira X, Zas R, Vila M, Sampedro L (2012). Early resistance of alien and native pines against two native generalist insect herbivores: no support for the Natural Enemy Hypothesis. Funct Ecol 26: 283-293.

Caño L, Escarré J, Vrieling K, Sans FX (2009). Palatability to a generalist herbivore, defence and growth of invasive and native Senecio species: testing the evolution of increased competitive ability hypothesis. Oecologia 159: 95-106.

Cipollini D, Mbagwu J, Barto K, Hillstrom C, Enright S (2005). Expression of constitutive and inducible chemical defenses in native and invasive populations of Alliaria petiolata. J Chem Ecol 31: 1255-1267.

de la Mata R, Zas R (2010). Transferring Atlantic maritime pine improved material to a region with marked Mediterranean influence in inland NW Spain: a likelihood-base approach on spatially adjusted field data. Eur J Forest Res 129: 645-658.

Donaldson JR, Kruger EL, Lindroth RL (2006). Competition- and resource-mediated tradeoffs between growth and defensive chemistry in trembling aspen (Populus tremuloides). New Phytol 169: 561-570.

Dunn OJ (1961). Multiple comparisons among means. J Am Stat Assoc 56: 52-64

Eigenbrode SD, Andreas JE, Cripps MG, Ding H, Biggam RC, Schwarzländer M (2008), Induced chemical defenses in invasive plants: a case study with Cynoglossum officinale L. Biol Invasions 10: 1373-1379.

Elton CS (1958). The Ecology of Invasions by Animals and Plants. University of Chicago Press: Chicago, IL.

Fry JD (2004). Estimation of genetic variances and covariances by restricted maximum likelihood using PROC MIXED. In Saxton AM (ed) Genetic Analysis of Complex Traits Using SAS. SAS Institute Inc: Cary, NC, pp 11-34.

Holland JB (2006). Estimating genotypic correlations and their standard errors using multivariate restricted maximum likelihood estimation with SAS Proc MIXED. Crop Sci 46: 642-654.

Hódar JA, Castro J, Zamora R (2003). Pine processionary caterpillar Thaumetopoea pityocampa as a new threat for relict Mediterranean Scots pine forests under climatic warming. Biol Conserv 110: 123-129.

Inderjit EH (2012). Exotic plant invasion in the context of plant defense against herbivores. Plant Physiol 158: 1107-1114.

Joshi J, Vrieling K (2005). The enemy release and EICA hypothesis revisited: incorporating the fundamental difference between specialist and generalist herbivores. Ecol Lett 8 704-714.

Joshi S, Tielbörger K (2012). Response to enemies in the invasive plant Lythrum salicaria is genetically determined. Ann Bot 110: 1403-1410.
Karban R (2011). The ecology and evolution of induced resistance against herbivores. Funct Ecol 25: 339-347.

Koricheva J, Nykanen H, Gianoli E (2004). Meta-analysis of trade-offs among plant antiherbivore defenses: are plants jacks-of-all-trades, masters of all? Am Nat 163: 64-75.

avery PB, Mead DJ (1998). Pinus radiata: a narrow endemic from North America takes on the world. In: Richardson DM (ed). Ecology and biogeography of Pinus. Cambridge University Press: Cambridge, pp 432-449.

Levine JM, Adler PB, Yelenik SG (2004). A meta-analysis of biotic resistance to exotic plant invasions. Ecol Lett 7: 975-989.

Littell RC, Milliken GA, Stroup WW, Wolfinger R, Schabenberger O (2006). SAS System For Mixed Models, 2nd edn SAS Institute Inc: Cary, NC.

Lombardero MJ, Vázquez-Mejuto P, Ayres MP (2008). Role of plant enemies in the forestry of indigenous vs. nonindigenous pines. Ecol App/ 18: 1171-1181.

Lynch M, Walsh JB (1998). Genetics and analysis of quantitative traits. Sinauer Assocs Inc: Sunderland, MA.

Maron JL, Vilà M (2001). When do herbivores affect plant invasion? Evidence for the natural enemies and biotic resistance hypotheses. Oikos 95: 361-373.

Maron JL, Vilà M, Bommarco R, Elmendorf S, Beardsley P (2004). Rapid evolution of an invasive plant. Ecol Monograph 74: 261-280.

Messina FJ, Durham SL, Richards JH, McArthur ED (2002). Trade-off between plant growth and defense? A comparison of sagebrush populations. Oecologia 131 $43-51$.

Moreira X, Sampedro L, Zas R (2009). Defensive responses of Pinus pinaster seedlings to exogenous application of methyl-jasmonate: Concentration effect and systemic response. Environ Exp Bot 67: 94-100.

Moreira X, Zas R, Sampedro L (2012a). Differential allocation of constitutive and induced chemical defenses in pine tree juveniles: a test of the optimal defense theory. PLoS One 7: e34006.

Moreira X, Zas R, Sampedro L (2012b). Methyl jasmonate as chemical elicitor of induced responses and anti-herbivory resistance in young conifer trees. In: Merillon JM, Ramawat KG (eds) Plant Defence: Biological control. Progress in Biological Control. Springer: Dordrecht, Netherlands, pp 345-362.

Moreira X, Zas R, Sampedro L (2012c). Quantitative comparison of chemical, biological and mechanical induction of secondary compounds in Pinus pinaster seedlings. Trees 26: 677-683

Mumm R, Hilker M (2006). Direct and indirect chemical defence of pine against folivorous insects. Trends Plant Sci 11: 351-358.

Oduor AM, Lankau RA, Strauss SY, Gómez JM (2011). Introduced Brassica nigra populations exhibit greater growth and herbivore resistance but less tolerance than native populations in the native range. New Phytol 91: 536-544.

Orians CM, Ward D (2010). Evolution of plant defenses in nonindigenous environments. Ann Rev Entomol 55: 439-459.

Parker JD, Hay ME (2005). Biotic resistance to plant invasions? Native herbivores prefer non-native plants. Ecol Lett 8: 959-967.

Rudgers JA, Strauss SY, Wendel JF (2004). Trade-offs among anti-herbivore resistance traits: insights from Gossypieae (Malvaceae). Am J Bot 91: 871-880.

Sampedro L, Moreira X, Zas R (2011a). Costs of constitutive and herbivore-induced chemical defenses in pine trees emerge only under low resources availability. $J$ Eco/ 99 : 818-827.

Sampedro L, Moreira X, Zas R (2011b). Resistance and response of Pinus pinaster seedlings to Hylobius abietis after induction with methyl jasmonate. Plant Ecol 212 397-401.

Wang Y, Siemann E, Wheeler GS, Zhu L, Gu X, Ding J (2012). Genetic variation in antiherbivore chemical defences in an invasive plant. J Ecol 100: 894-904.

Yang RC (2002). Likelihood-based analysis of genotype-environment interactions. Crop Sci 42: 1434-1440.

Zas R, Moreira X, Sampedro L (2011). Tolerance and induced resistance in a native and an exotic pine species: relevant traits for invasion ecology. J Ecol 99: 1316-1326.

Zas R, Sampedro L, Moreira X, Martíns P (2008). Effect of fertilization and genetic variation on susceptibility of Pinus radiata seedlings to Hylobius abietis damage. Can $\mathrm{J}$ Forest Res 38: 63-72.

Supplementary Information accompanies the paper on Heredity website (http://www.nature.com/hdy) 